\section{Modelo para el estudio y atención del maltrato infantil en el Instituto Nacional de Pediatría: enfoque en derechos humanos, ecológico e interdisciplinario}

\author{
Model for the study and care \\ of child abuse in the National \\ Institute of Pediatrics: focus \\ on human rights, ecological \\ and interdisciplinary approach
}

El maltrato infantil es un atentado a los derechos fundamentales de niñas, niños y adolescentes, producto de prácticas de socialización que aprueban el uso de la violencia y el poder hacia los más vulnerables. El escenario es más complejo debido a que el maltrato infantil ocurre con mayor frecuencia dentro de la familia, entorno que debería proveer confianza, afecto y protección.

Además de las posibles consecuencias físicas, psicológicas y sociales, el maltrato infantil tiene un impacto económico que abarca los costos de hospitalización, tratamiento por motivos de salud física y psicológica, así como los servicios sociales y sanitarios a largo plazo como rehabilitación física o mental. Estas consecuencias tienen un impacto negativo importante y limitan el desarrollo social y económico de los países; por ello es necesario que desde las diferentes instancias implicadas en la protección de la niñez se desarrollen programas de acción en los que, además de proporcionar medidas de prevención, se implementen modelos de intervención temprana que ayuden a reducir los efectos.

Modelo para el estudio y la atención del maltrato infantil

A partir del 2014 en la Clínica de Atención Integral al Niño Maltratado, del Instituto Nacional de Pediatría, se reestructuró el plan de trabajo; actualmente nuestras actividades se encuentran sistematizadas, coordinadas y basadas en evidencia científica. El modelo integra tres perspectivas articuladas: enfoque en derechos humanos, ecológico e interdisciplinario.

Enfoque en derechos humanos: el trabajo basado en derechos nos permite reconocer $y$ 
respetar a las niñas, niños y adolescentes más allá del discurso, nos convoca a visualizarles como personas titulares de derechos al igual que los adultos pero con consideraciones especiales debido a su etapa de desarrollo. Los derechos humanos son garantías jurídicas y exigencias éticas universales que protegen a todos los seres humanos contra acciones $u$ omisiones que interfieran con su dignidad; por ello, el 10 de junio de 2011 se publicó en el Diario Oficial de la Federación el decreto por el cual se reconocen constitucionalmente los derechos humanos de las personas y establecen las garantías para lograr su efectiva protección. El maltrato infantil se considera un atentado a los derechos de niñas y niños, en este sentido su estudio nos obliga a adoptar un nuevo paradigma en donde se deja de concebir a los derechos de la niñez como un discurso vacío o una lista de normativas y declaraciones, por el de una infancia y adolescencia con capacidades y potencialidades propias, titulares plenos de derechos.

Enfoque ecológico: con la finalidad de acercarnos a la comprensión del maltrato infantil se propone un enfoque ecológico que tiene como fundamento el estudio del ser humano en su acepción interna y la influencia del entorno en que se desarrolla; es decir, el estudio de los factores históricos, biológicos, sociales, culturales, económicos, políticos, su relación con otros individuos y su interacción con los distintos sistemas. El modelo ecológico, además de proponer una visión integral, permite identificar factores de riesgo y protectores, lo cual ayudará a establecer acciones preventivas y de atención temprana.

Enfoque interdisciplinario: el estudio y atención del maltrato infantil requieren, por su complejidad y multicausalidad, analizarse de forma interdisciplinaria, lo que implica la integración de métodos desde diferentes áreas; la filosofía de esta práctica es la búsqueda siste- mática de integración de teorías fundamentadas científicamente para llegar a un consenso. La interdisciplinariedad promueve intercambios que producen enriquecimiento y transformación mutua, implica un reto para el estudio y análisis de situaciones de alta complejidad como lo es el maltrato infantil, además, atenta contra la posibilidad de fragmentación de los fenómenos.

Consideramos que lo fundamental en el estudio del maltrato infantil es enfocarse en un trabajo comprometido, sin saberes absolutos, encauzando la búsqueda constante de conocimientos y modelos que permitan comprender y atender los problemas que plantea cada caso; siempre y en todo momento, con una visión humanista.

En la Clínica de Atención Integral al Niño Maltratado del Instituto Nacional de Pediatría tenemos un claro compromiso y una firme convicción de brindar una atención especializada, integral y basada en derechos humanos al paciente y a su familia, anteponiendo en todo momento el respeto a la dignidad; para ello proponemos nuestro modelo de estudio y atención.

Para mayor información, revisar el manual para el estudio y atención del maltrato infantil de la Clínica de Atención Integral al Niño Maltratado.

\section{Lecturas recomendadas}

1. Organización Mundial de la Salud. Prevención del maltrato infantil: Qué hacer, y cómo obtener evidencias. 2009

2. Organización de Naciones Unidas (2006). La violencia contra niños, niñas y adolescentes. Informe de América Latina en el marco del Estudio Mundial de las Naciones Unidas 2006. Disponible en: http://www.crin.org/docs/ UNVAC_Estudio_violencia_LA.pdf

3. Diario Oficial de la Federación. DECRETO por el que se modifica la denominación del Capítulo I del Título Primero y reforma diversos artículos de la Constitución Política de 
los Estados Unidos Mexicanos. http://dof.gob.mx/nota_detalle.php?codigo $=5194486 \&$ fecha $=10 / 06 / 2011$

4. Constitución Política de los Estados Unidos Mexicanos. Texto vigente al 28 febrero $2014 \mathrm{http}$ ://www.ordenjuridico. gob.mx/constitucion.php

5. Derechos de los Niños, Niñas y Adolescentes. Convención sobre los Derechos del Niño. Ley Nº 23.849. UNICEF 2004. http://www.unicef.org/mexico/spanish/mx_Convencion_ Derechos_es_final.pdf

6. Morin E. La epistemología de la complejidad. Gaceta de Antropología 2004;20:43-48.
7. J Piaget. La interdisciplina desde la teoría de los sistemas complejos. Ciencias 2005;79:4-12.

Dra. Corina A. García Piña

Pediatra

Coordinadora de la Clínica de Atención Integral al Niño Maltratado Instituto Nacional de Pediatría 